\title{
Ação afirmativa para ingresso de negros no ensino superior: formação multinível da agenda governamental
}

Tatiana Dias Silva

Universidade de Brasília (UnB) e Instituto de Pesquisa Econômica Aplicada (Ipea)

Este texto analisa o processo de formação da agenda governamental que passou a considerar o problema da desigualdade racial no ensino superior. Procura-se identificar os elementos que permitiram que uma situação conhecida há tanto tempo passasse a receber atenção da sociedade e do governo. Para tanto, recorreu-se aos modelos de Múltiplos Fluxos e do Equilíbrio Pontuado. Além de pesquisa documental, procurou-se incorporar a perspectiva dos atores por meio de análise de audiência pública organizada pelo Supremo Tribunal Federal (STF), cujo tema era a política de cotas para estudantes negros na Universidade de Brasília (UnB). Como resultado, verificou-se que os fluxos dos problemas, alternativas e da política criaram janela de oportunidade para o tema, tanto no nível das instituições de ensino superior (IES) como na política nacional. Processos de mudança multinível se mostraram cruciais para abrir espaço na agenda governamental para essa "nova" temática.

Palavras-chave: agenda pública - Brasil, ação afirmativa - raça, inclusão social, acesso à educação - ensino superior

[Artigo recebido em 23 de janeiro de 2017. Aprovado em 26 de setembro de 2017.] 
Acción afirmativa para ingreso de negros en la enseñanza superior: formación multinivel de la agenda gubernamental

Este trabajo analiza el proceso de formación de la agenda de gobierno que ha considerado el problema de la desigualdad racial en la educación superior. Se trata de identificar los elementos que permitieron que una situación conocida pase tanto tiempo para recibir la atención de la sociedad y el gobierno. Por lo tanto, se utilizaron los modelos de múltiples flujos y equilibrio puntuado. Además de la investigación documental, se intentó incorporar la perspectiva de los actores a través de un análisis de audiencia pública organizada por el Tribunal Supremo (STF), cuyo tema era la política de cuotas para estudiantes negros de la Universidad de Brasilia (UNB). Como resultado, se encontró que los flujos de los problemas, de las alternativas y de la política crearan una ventana de oportunidad para el tema, tanto a nivel de instituciones de educación superior (IES) como en la política nacional. Procesos de cambio multinivel fueron cruciales para hacer espacio en la agenda del gobierno para este "nuevo" tema.

Palabras clave: agenda pública - Brasil, acción afirmativa - raza, inclusión social, acceso a la educación - enseñanza superior

\section{Affirmative action for afro-brazilians to access higher education: multilevel setting of the governmental agenda}

This text analyses the process of the formation of the governmental agenda, which began to considerate the problem of racial inequality in higher education. It is trying to identify the elements which allow a situation, already quite well known for some time, to receive attention by society and the government. All in all, it goes back to the models of Multiple Streams and Punctuated Equilibrium. Besides the document research, it has tried to incorporate the analysis from the perspective of the actors of the public audition, which has been organized by the High Court (STF), and which topic was the quota policy for black students at the Universidade de Brasilia (UnB). As a result, it confirmed that the various streams of problems, different solutionary choices and policies raise awareness for the topic, as well as on the level of higher education as on the level of national politics. Multilevel processes of change prove themselves crucial to open space on the government agenda for this "new" topic.

Keywords: public agenda - Brazil, affirmative action - race, social inclusion, access to education - higher education 


\section{Introdução}

A diferença de oportunidades entre negros e brancos sempre foi marca estrutural das desigualdades no Brasil. A história de séculos de exploração foi alimentada inclusive por medidas governamentais que restringiam a integração da população negra liberta (THEODORO, 2008). O racismo travestido de ciência deu lugar, ao longo da primeira metade do século 20 , a um discurso de elogio da mestiçagem e de democracia racial (OsóRıO, 2008). A negação do racismo constituía-se em política de Estado, a despeito das denúncias constantes dos movimentos sociais negros (Rıos, 2012). Desse modo, ao passo que, em 1966, o chanceler brasileiro, em discurso na Organização das Nações Unidas (ONU), afirmava que o Brasil era "um exemplo proeminente [...] de uma verdadeira democracia racial" (SILVA, 2008, p. 69), em 1970, foi retirada do censo demográfico a questão sobre cor, presente desde 1872 (SILVA, 2013). O problema era assim constantemente negado.

A despeito da retórica dos governos e da visão da sociedade, ora pendente para o mito da democracia racial, ora ignorando solenemente a questão e transformando-a em tabu, as desigualdades raciais no país mostravam-se expressivas em diferentes campos da vida social. Na educação, essas desigualdades não eram apenas impressionantes, mas fundamentais para o cerceamento do acesso da população negra a outros direitos. Não por acaso, o acesso à educação antirracista e de qualidade sempre foi uma das bandeiras prioritárias dos movimentos sociais negros (SANTOS, 2014).

$\mathrm{Na}$ área da educação, a desigualdade no ensino superior sempre se apresentou com maior magnitude, dadas as restrições de acesso geral. Mesmo com persistentes demandas dos movimentos negros e denúncias de especialistas, essas últimas especialmente a partir dos anos 1980, a situação ainda não era considerada problema relevante. Assim, embora as desigualdades raciais fossem discutidas em círculos de especialistas nas décadas mais recentes, nem os relatórios oficiais ou processos de avaliação de políticas públicas incorporavam a análise racial para averiguar a efetividade dos programas governamentais. Embora o IBGE tenha coletado dados raciais desde o século 19 , os registros administrativos eram marcados pela ausência de dados desagregados, o que configurava uma verdadeira "invisibilidade estatística” (PAIXÃo; RosSETO, 2012).

Cabe destacar que, em diferentes campos, houve redução das desigualdades raciais nos últimos anos, em que pese sua persistente magnitude. Nos dados de acesso ao ensino superior, verifica-se também desigualdade persistente, com inflexão a partir dos primeiros anos da década de 2000. Em 1992, apenas 4,6\% dos jovens entre 18 e 24 anos frequentavam o ensino superior (1,5\% dos jovens negros 
e 7,2\% dos brancos). Em 2013, o acesso melhorou para ambos os grupos $(10,7 \%$ dos jovens negros e $23,4 \%$ dos brancos). As diferenças, ainda que tenham sofrido redução - especialmente na última década -, permaneceram expressivas. Em 1992, a taxa de frequência líquida dos jovens negros era apenas $21 \%$ da taxa dos jovens brancos. Em 2013, essa razão passou para 46\% (INSTITUTO DE PESQUISA ECONÔMICA APLICADA, 2015). Em parte, a redução das desigualdades nessa etapa esteve ligada à expansão das vagas no ensino superior ${ }^{1}$.

Além desse fator, os últimos anos testemunharam a implementação de programas de ação afirmativa que incluíram, como público-alvo, a população negra. Além de ações afirmativas de âmbito privado, a exemplo de programas de bolsas ou cursinhos preparatórios para comunidades carentes e estudantes negros, em 2005 foi institucionalizado o Programa Universidade para Todos (Prouni) ${ }^{2}$, que previa bolsas de estudo para estudantes com baixa renda, negros e indígenas. Ademais, desde 2001, foram criados, em diferentes formatos, programas de ação afirmativa em instituições de ensino superior (IES) brasileiras. A primeira iniciativa foi encetada na Universidade do Estado do Rio de Janeiro (UERJ) e na Universidade Estadual do Norte Fluminense (UENF), por meio de lei estadual, com cotas sociais e posteriormente inclusão de cotas raciais ${ }^{3}$. Já em 2004, a Universidade de Brasília (UnB) consolidou-se como a primeira instituição federal de ensino superior com cotas, nesse caso, especificadamente para negros. Em 2012, havia 129 IES com algum tipo de ação afirmativa, em 535 cidades, entre as quais 51 eram universidades federais e 52 IES tinham programas com cotas ou subcotas para negros. Os outros critérios de ação afirmativa, isolados ou combinados, envolviam estudantes de escola pública, indígenas, pessoas com deficiência, quilombolas, baixa renda ou critério regional (INSTITUTO DE INCLUSÃO NO ENSINO SUPERIOR E NA PESQUISA, 2012).

Essa mudança na política e na forma de abordar a questão racial é deveras impressionante. Após séculos de escravidão e décadas de construção e reprodução do mito da democracia racial, o modo de encarar as desigualdades raciais em um campo tão exclusivo e eivado de privilégios havia, não sem resistência, sofrido alterações estruturais. A partir dos anos 2000, a desigualdade no acesso de negros ao ensino superior passou a ser considerada como tema relevante e a ser objeto da atenção e decisão em nível governamental - tanto em organizações públicas de ensino superior como no nível federal.

\footnotetext{
${ }^{1}$ As matrículas no ensino superior (graduação presencial) passaram de 2.694 .245 em 2000 (32,9\% nas IES públicas) para 6.152.405 matrículas em 2013 (28,9\% nas IES públicas) (INSTITUTO NACIONAL DE EstUdos E PESQUISAS EdUCACIONAIS, 2001, 2014a).

2 Lei no 11.096 , de 13 de janeiro de 2005.

${ }^{3}$ Lei no 3524, de 28 de dezembro de 2000, e Lei no 4.151, de 4 de setembro de 2003, do Estado do Rio de Janeiro.
} 
Questiona-se, então, quais os elementos que permitiram que uma situação de desigualdade tão pujante no contexto brasileiro há tanto tempo e tão negligenciada pelos governos passasse a receber atenção da sociedade e do governo e a ser tema recorrente de acalorados debates. Por meio de quais mecanismos, a desigualdade racial no acesso ao ensino superior ganhou espaço e consolidou-se como uma legislação nacional em 2012?

Diante dessa problemática, este texto tem como objetivo analisar o processo de inclusão do tema da desigualdade racial no acesso ao ensino superior na agenda governamental. Compreender melhor esse processo pode contribuir com a análise da implementação e resultados dessa política tão recente, além de identificar fatores críticos que devam ser monitorados para sua eficácia. Pode contribuir também para melhor compreensão e intervenção em outras políticas afirmativas levadas a cabo nos últimos anos, como as cotas para ingresso na administração pública.

Para analisar essas questões e a trajetória dessa mudança institucional e social na realidade recente brasileira, será adotada a perspectiva de formação de agenda (agenda-setting) para discutir os principais fluxos, atores e visões compartilhadas que nortearam o debate e permitiram essa mudança. Para tanto, será utilizado como referencial teórico a abordagem dos Múltiplos Fluxos, originalmente desenvolvida por John Kingdon (2007a, 2007b, 2011), complementada pelo modelo do Equilíbrio Pontuado, cujo desenvolvimento inicial é atribuído a Jones e Baumgartner (2012).

O modelo conceitual da pesquisa procura analisar a formação de agenda por meio da conjunção entre múltiplos fluxos (problema, política e alternativas), incorporando uma dimensão multinível. Por meio de pesquisa documental, procura-se reconstituir esses elementos e compreender melhor o processo de formação de agenda.

Além desta introdução, este texto apresenta mais cinco seções. Na seguinte, será apresentado o referencial teórico que embasa esta análise. Em seguida, serão detalhados os procedimentos metodológicos e o modelo de análise, para, depois, apresentarem-se os resultados. Por fim, são apresentadas considerações finais, que incluem as limitações da investigação e possibilidades de novos estudos.

\section{A formação da agenda governamental}

\section{A abordagem dos múltiplos fluxos: como surge um problema}

No modelo de Múltiplos Fluxos (MF) de Kingdon (2007b, 2011), a preocupação principal não está direcionada às alternativas que vão ser deliberadas ou a como ocorrem os processos decisórios no âmbito dos poderes Executivo ou Legislativo. 
Sua atenção se concentra no modo e motivação pelos quais alguns problemas recebem atenção e outros não. Sua análise volta-se aos momentos pré-decisórios, em uma abordagem que rechaça, por um lado, a concepção de racionalidade total, e por outro lado, uma visão sequencialista de políticas públicas. Nesse sentido, se afilia a uma concepção mais fluida, em que diferentes processos, organizados por lógicas distintas, previsíveis ou não, se encontram em momentos propícios, gerando uma "janela de oportunidade" para a política pública. Assim, uma situação pode ser reconhecida como um problema e ser alçada à agenda decisória governamental. Esse modelo se aproxima da proposta do Garbage Can (GC), ou lata de lixo, de March e Olsen, avançando, segundo Zahariadis (2007), em seu escopo e alcance.

Kingdon $(2007 a, 2011)$ identifica a formulação de políticas públicas como conjunto de processos que envolve o estabelecimento de uma agenda, a especificação das alternativas, a escolha e a implementação dessa opção. Nas duas primeiras fases (pré-decisórias), atuam três correntes: reconhecimento do problema, formulação de propostas e soluções e a dinâmica política.

A agenda consiste em uma relação de temas ou problemas alvos de séria atenção em um determinado momento. Enquanto há uma agenda de governo, com temas a serem objeto de atenção, há também uma agenda de decisão, cujo conteúdo será submetido à apreciação. Por conseguinte, a formação da agenda consiste em filtrar temas para consolidar lista de assuntos que vão merecer atenção do governo, a partir da atuação de três fluxos centrais.

Nofluxo dos problemas, analisam-se tanto os meios pelos quais um problema passa a ser conhecido, como os fatores que levam à crença de que, uma vez reconhecido, a situação exige decisão no sentido de alterá-la. Os meios de reconhecimento de um problema podem envolver indicadores, eventos-foco (como crises, acidentes ou símbolos) e feedback (formal ou informal) de programas e ações do governo. Por sua vez, situações passam a ser percebidas como problemas quando se acredita que é preciso fazer algo para alterá-las. Situações que contrariam valores importantes, ou que apresentem relevância por comparação histórica ou com outras unidades de análise, ou ainda que sejam submetidas à mudança de categoria de análise de um fenômeno podem funcionar como elementos de convencimento para ação governamental. Ainda assim, os problemas podem igualmente desaparecer da agenda, por já estarem sendo tratados, por frustração ao não se conseguir resolvêlos ou quando os meios que chamaram atenção para o problema mudam ou ainda quando novas questões assumem preponderância na agenda.

Kingdon (2007b, 2011) chama de empreendedores da política atores diversos que, em suas áreas de atuação e especialidade, se esforçam para que as instâncias decisórias reconheçam o problema. Empreendedores da política são aquelas 
pessoas dispostas a investir recursos na promoção da política. Agem por interesse próprio, por uma causa, por reconhecimento ou por valores. Atuam no fluxo dos problemas, na indicação de alternativas e na viabilização das três correntes.

Em uma dinâmica diferente do fluxo do problema, o fluxo da política (politics) funciona com a lógica do consenso por negociação, mais do que por persuasão. Os participantes desse fluxo podem ser visíveis (políticos, alto escalão do governo) e geralmente são estes que definem as agendas. No entanto, os participantes invisíveis atuam nos bastidores e geralmente têm maior poder na escolha e defesa das alternativas (burocratas, acadêmicos, especialistas). Nesse fluxo, a opinião pública sobre determinado tema e a ação de grupos de interesse organizados atuam fortemente na construção de um ambiente de debate e defesa de posições. Igualmente, a mudança de governo por si só pode permitir que uma situação passe a ser analisada sob outro prisma, tanto por diferenças ideológicas em relação ao governo anterior ou mesmo pela assunção de novos gestores e abertura a novas ideias.

Por fim, o fluxo das políticas públicas (policies) comporta as alternativas a serem selecionadas e defendidas. Elas são escolhidas por alguns critérios, como congruência com os valores dos membros da comunidade de especialistas, viabilidade financeira, antecipação de restrições (financeiras, sociais etc.) no sentido de se identificar um custo tolerável, em um processo de "amaciamento", no qual "teóricos" de uma solução defendem e difundem suas convicções.

Em contraste com um processo sequencial, esses fluxos se sobrepõem e funcionam sob lógicas e tempos diferenciados. Para uma questão se posicionar na agenda de decisões, todavia, geralmente deve haver uma conexão entre os três fluxos. Quando ocorrem apenas conexões parciais, é provável que não haja força suficiente para promover uma situação ao status de problema. Por exemplo, problemas que chegam à agenda de governo sem propostas de solução têm pouca chance de serem efetivamente apreciados.

As janelas de políticas públicas são abertas por eventos tanto na área dos problemas como da política (janelas de problemas e janelas de política). Quando uma janela se abre, geralmente são apresentadas muitas propostas e muitos problemas, ainda que nem todos cheguem a ganhar atenção. Assim, Kingdon (2007b, p. 240) responde à sua questão inicial, de como as ideias chegam a ser consideradas: "[...] os eventos não ocorrem organizadamente em estágios, passos ou fases. Em vez disso, dinâmicas independentes que fluem pelo sistema ao mesmo tempo, cada uma com vida própria e similar às outras, unem-se quando se abre uma janela de oportunidades". 
Por sua vez, quando há sucesso em uma agenda de decisão, podem-se criar oportunidades para aprovação de pautas similares (spillover), uma vez que o êxito vai mobilizar os empreendedores, influenciar o processo e deslocar a ação da coalização vencedora. Embora Kingdon (2011) não o cite, o efeito reverso também pode ser verdadeiro. Cabe salientar que Kingdon (2011) sempre defende o caráter probabilístico de sua abordagem, apresentando condições em que há maiores chances de ocorrer um determinado fenômeno, mas não isentando a análise de outras condicionantes não relacionadas ou mesmo de eventos aleatórios.

Zahariadis (2007), além de introduzir explicitamente o componente da ambiguidade, defende o uso da perspectiva dos MF para todo o processo de elaboração de políticas públicas e não apenas para sua formulação. Por ambiguidade, entendem-se diferentes formas de ver um fenômeno, que, muitas vezes, podem ser inconciliáveis. Se incerteza diz respeito à inabilidade de prever um evento, mais informação pode reduzi-la; no entanto, no que diz respeito à ambiguidade, mais informação pode até mesmo aumentá-la.

Segundo Zahariadis (2007), na abordagem oferecida por Kingdon (2011), decisões coletivas não são o agregado de decisões individuais, mas sim o resultado de um processo de forças estruturais e de um processo cognitivo e afetivo moldado pelo contexto. A escolha é vista a partir de uma "lata de lixo" onde os participantes, envolvidos ou não na decisão, depositam problemas e soluções não relacionados. Ninguém coordena diretamente o processo de escolha.

Kingdon adapta o modelo da GC para analisar o resultado de políticas dos EUA. Nessa análise, destaca três aspectos: a) participação fluida: tempo e esforço dedicado à decisão é variável. Há grande rotatividade entre políticos e burocratas, que passam de decisão a decisão; b) preferências problemáticas: antes de formar preferências, participantes são obrigados a tomar decisões, espremidos pelo tempo e por diferentes pressões; c) tecnologia não é clara: frequentemente os membros da organização não sabem como as outras áreas funcionam, têm vaga ideia sobre o que acontece em outros departamentos. As fronteiras organizacionais não são claras e há muito ruído e conflitos entre as áreas. Por fim, acabam utilizando a tentativa e erro e se baseando no que deu certo no passado para construir novas decisões (ZAHARIADIS, 2007).

Nesse contexto, a manipulação é um esforço importante para controlar ambiguidade. É direcionada a fim de criar sentido para os fenômenos. Desse modo, a informação é um elemento não neutro, pois é constantemente manipulada. Destarte, Zahariadis (2007) avalia que o foco não é apenas entender como a construção de significados ocorre no contexto de decisão, mas a forma estratégica 
como instituições, símbolos e significados podem ser utilizados para alterar a dinâmica das decisões.

Por fim, cabe pontuar as críticas dirigidas à abordagem dos MF e elencadas por Zahariadis (2007). O modelo do GC foi criticado pela falta de demonstração empírica das conclusões, que partem dos pressupostos de maneira direta. O modelo MF, consequentemente, herdaria esses problemas. $\mathrm{O}$ autor, no entanto, pontua que $\mathrm{O}$ MF se baseia no GC, mas toma outra direção. Por exemplo, enquanto um apresenta a decisão como resultado de forças fortuitas, o MF aponta a decisão como um elemento deliberado dos empreendedores da política. Por conseguinte, discorda de críticos que afirmaram que as falhas do modelo GC invalidam seus seguidores e ainda destaca a contradição, uma vez que os mesmos críticos elogiam o modelo de MF. Também cita teste estatístico sobre atuação das MF realizado por Travis e Zahariadis, o que comprovaria a possibilidade de teste de suas hipóteses.

Por fim, salienta que o uso do MF supera a perspectiva de ciclos ou estágios de políticas públicas, que, comprovadamente, não acontecem de forma sequencial. O uso do MF possibilita análises mais complexas das correntes que produzem e afetam as políticas públicas.

À guisa de conclusão, destaca-se, da análise de Zahariadis (2007), que as lentes oferecidas pelo MF conseguem superar a dicotomia entre voluntarismo e determinismo, colocando em relevo o papel da ação do indivíduo, mas admitindo a força das instituições. Em meio a normas e instituições, há espaço para manipulação dos agentes, em um contexto de ambiguidades, acasos e incertezas, considerando a racionalidade limitada e a complexidade de processos independentes e interrelacionados que conformam os problemas, a política e alternativas de ação governamental.

O MF também é criticado devido à aleatoriedade do modelo. Essa crítica é contraposta com a existência de variáveis intermediárias em cada fluxo, o que cria condições propícias para seu fortalecimento, sob uma visão contingencial. Outro ponto abordado é a interdependência dos fluxos no modelo de $M F$, em vez da independência inicialmente proposta por Kingdon (2011). Como destaca Capella (2006), Kingdon (2011) posteriormente admite a interdependência em momentos alheios à formação das janelas. Algumas dessas questões são retomadas por Gottems et al. (2013, p. 518). Para esses autores, os principais pontos negativos identificados na abordagem dos múltiplos fluxos "referem-se à baixa capacidade preditiva, à subespecificação das forças causais, à concentração nos fatores situacionais e temporais, sua ênfase descritiva e as dúvidas sobre o caráter incremental na especificação de alternativas" (GotTEMs et al., 2013, p. 518). 
Alguns críticos ressentem-se de uma abordagem exatamente mais "paradigmática". Weible e Schlager (2016) defendem que, apesar dos seus trinta anos, o MF precisa de aprofundamento para avançar no conhecimento sobre política pública e seu processo. Assim, sugerem o uso de um framework com linguagem e conceitos comuns e a utilização de métodos de coleta e análise de dados que permitam análise comparativa e consequente acúmulo de conhecimento generalizável. Reconhecem, no entanto, que essas duas primeiras propostas convergem para uma visão positivista. Não obstante, os autores também acrescentam a possibilidade de utilização de análise discursiva para compreensão da MF, convergindo para uma abordagem pós-positivista que privilegie mais a interpretação e os argumentos do que as relações de causalidade.

Por sua vez, uma das contribuições teóricas a pontadas é a inspiração que propiciou para outras abordagens, como é o caso de teorias evolucionárias, que procuram identificar como ambientes influenciam na estabilidade ou mudança das políticas e o papel dos atores na adaptação ou ruptura. Constrangidos pelo ambiente, os atores têm papel fundamental em promover o encontro dos três fluxos, permitindo a finalização de um processo de escolha de alternativas e reconhecimento de problemas (CAIRNEY; JONES, 2016). Esse seria o caso da Punctuated-Equilibrium Theory (PET).

Em um contexto de ambiguidades, construção de significados e disputa entre diferentes atores, procura-se analisar como a questão racial, em especial a desigualdade racial no acesso ao ensino superior, passou a ser tema da agenda de governo. Para tanto, a despeito de suas limitações, a abordagem dos MF oferece uma ampla possibilidade analítica, ao mapear processos complexos que culminaram em uma janela de oportunidade que se logrou decisiva para o tema no país. Todavia, esse processo não se deu de forma direta, envolvendo, ao longo do tempo, diferentes arenas e níveis de atuação governamental. Analisar o processo de formação da agenda governamental federal não pode negligenciar as dinâmicas anteriores nas IES. Assim, como recomendam Gottems e outros (2013, p. 518), recorreu-se ao uso de outros referenciais para suprir lacunas relativas ao "peso das instituições, do tempo e da historicidade das mudanças políticas". Nesse caso, elementos do modelo do equilíbrio pontuado foram incorporados à análise especialmente para contribuir com a reflexão da formação da agenda em diferentes tempos e níveis institucionais. 


\section{Modelo do Equilíbrio Pontuado: a imagem do problema e os subsistemas na formação da agenda}

O objetivo da Teoria do Equilíbrio Interrompido ou Pontuado (PunctuatedEquilibrium Theory - PET) é explicar como e por que ocasionalmente ocorrem rupturas, embora os processos políticos sejam geralmente caracterizados por inércia, incrementalismo e estabilidade. A abordagem tenta contemplar estabilidade e crise, diferentemente da maioria dos modelos que se dedicam ou conseguem explicar um dos estágios apenas. Como o modelo de MF, apresentado por Kingdon (2011), o PET também tem foco na definição de problemas e formação de agenda. A definição de problemas é conformada pelo discurso público e, quando esse se altera, a política pode ser reforçada ou questionada. No segundo caso, mudanças mais significativas são geradas.

Para Jones e Baumgartner (2012), formuladores do PET, as mudanças de grande monta ocorrem entre períodos de longa estabilidade e não advêm apenas de eventos externos, como eleições, mas também se desenvolvem no interior dos sistemas. Quando um subsistema não pode conter as demandas por mudança, elas transbordam o nível macropolítico de decisão.

Essa abordagem vai de encontro ao modelo padrão norte-americano de análise de mudanças nas políticas à época. Esse modelo se baseava nas mudanças promovidas pelo processo eleitoral, que alterariam os formuladores de política e, consequentemente, o tipo de política que seria desenvolvido. Jones e Baumgartner (2012) destacam que, contudo, esse modelo não apresenta explicações convincentes quando confrontado com algumas situações. Por exemplo, mudanças relevantes podem acontecer sem precedência de eleições. Ademais, nesse modelo, não há espaço para priorização das alternativas. Ainda, convém pontuar que as posições entre os partidos não são fixas, elas comportam alternativas matizadas. Desse modo, concluem que eleições são importantes, mas não explicam todas as grandes mudanças. Alia-se a esse equívoco o fato de que o foco no incrementalismo levou os teóricos a menosprezar as grandes mudanças pontuais (JONES; BAUMGARTNER, 2012).

Por conseguinte, esses autores propõem nova abordagem que considere não apenas o incrementalismo, mas possibilidades de mudanças abruptas. O mecanismo que conduziria esses dois processos seria a natureza distinta de feedback atuante nos subsistemas e no nível macropolítico. As pressões por mudança passam por processos tanto de feedback negativo como de feedback positivo: "no primeiro caso, um distúrbio é recebido com ações de compensação, em um processo semelhante a um termostato. Nesse último, a mudança resulta em mudança, gerando um 
impulso muito mais poderoso para a mudança do que se poderia esperar" (JONES; BAUMGARTNER, 2012, p. 3).

True et al. (2007) acrescentam que, no processo de feedback positivo, uma mudança, ainda que modesta, causa efeitos amplificados. Por sua vez, o feedback negativo mantém a estabilidade do sistema e é responsável pelas mudanças incrementais. Assim, pequenas mudanças podem causar grandes efeitos. O que determina se um processo vai se desenvolver por feedback positivo é a interação entre mudanças na imagem e arena da política.

A imagem da política seria moldada pela combinação entre informação empírica e apelo emotivo. Uma mesma política pode ter atenção em um nível do governo e ser neglicenciada por outro, devido a seus diferentes subsistemas, participantes, limitações, enfim, suas características. Quando apenas uma imagem é dominante em determinado subsistema, fala-se em monopólio da política. Esse conceito refere-se a um subsistema reconhecido que concentra a formulação de políticas em uma determinada área, que pode apresentar feedback negativo por geralmente "amortecer" pressões por mudanças. Assim, tal como as comunidades paradigmáticas, "esses monopólios são responsáveis pela manutenção da estabilidade na produção de políticas públicas e pela restrição de novas questões à agenda governamental" (CAPELLA; BRASIL, 2015, p. 463).

Quando a forma de ver o problema muda ou novas dimensões emergem, grupos e pessoas fora do "monopólio da política" podem exercer pressão suficiente para romper o subsistema ou para forçar divisão do espaço e o estabelecimento de novas regras. Essas novas regras passam a formar um novo equilíbrio que permanece quando as pressões arrefecem.

Para Jones e Baumgartner (2012), o equilíbrio pontuado é o comportamento mais comum na formação de políticas norte-americanas. No entanto, ressaltam que essa constatação pode esconder problemas internos muito diferenciados. Alertam que arranjos institucionais (como gestão de conflitos ou aprendizagem organizacional) podem reduzir a magnitude das mudanças mais amplas (punctuations). A resistência à mudança (friç̧ão) seria resultado da atuação das regras institucionais do sistema político (rotinas, formas de pensar, cultura, normas), que funcionam no nível cognitivo, organizacional e institucional. Assim, as mudanças de grande impacto ocorrem não apenas por meio de pressões externas, como também resultam da acumulação de esforços, ao longo do tempo, para combater as resistências (fricção).

True et al. (2007) tratam das friç̧ões apontadas por Jones e Baumgartner (2012), referindo-se a elas como as maiores fontes de custo para transformar inputs em políticas. Os custos seriam de natureza cognitiva, assumidos pelos atores políticos que se envolvem no processo de reconhecer os sinais de um problema, 
dar atenção, contextualizar e propor sugestões; e de natureza institucional, em que as regras do ambiente de formulação de política tendem a manter a estabilidade. Por sua vez, as instituições de formulação de políticas parecem incrementar o atrito de determinados problemas para formar pressão suficiente para superar barreiras institucionais, a exemplo dos empreendedores de política de Kingdon (2011).

O modelo PET se baseia em uma generalização da abordagem do equilíbrio pontuado. Em sua versão mais ampla, com base na visão de racionalidade limitada, enfatiza-se o papel do processamento de informação no sistema de formulação de política, que envolve coleta, organização, interpretação e priorização de informação. O processamento de informação pode ser explícito ou não, e geralmente é marcado por incerteza e ambiguidade. Mais do que assimetria de informação reforçada em outros modelos, o PET destaca o excesso de informação e a seletividade da atenção dos formuladores de política, que simplesmente ignoram parte da informação disponível por dificuldade de processar tudo. Essa desproporção no processamento de informações compromete a priorização dos problemas para ação governamental (JONES; BAUMGARTNER, 2012).

Como destacam True et al. (2007), o sistema político tem um processamento serial, a partir do qual não se pode dedicar a muitos assuntos em um só momento. Há, no entanto, subsistemas políticos que processam, em paralelo, diferentes questões, mas tendem a ser insulados e a ter pouca capacidade de promover mudanças radicais. Algumas vezes, todavia, o processamento paralelo ganha espaço e o assunto passa a ser processado de forma serial pelo sistema político. $O$ assunto sai do nível de subsistema para o nível macropolítico geralmente por mudança nas definições do problema, intensificação da atenção provocada pela mídia ou por públicos mais amplos. A dinâmica da atenção pode ser disparada por um evento ou por acúmulo de problemas ao longo do tempo. Com efeito, o acesso ao nível macropolítico é necessário para mudanças radicais, mas não suficiente.

True et al. (2007) analisam a dinâmica orçamentária norte-americana à luz da Teoria do Equilíbrio Pontuado e concluem que as pontuações ocorrem tanto em sentido top-down como bottom-up, sendo que a primeira direção é de mais fácil comunicação. A repercussão bottom-up é geralmente amortecida pelo insulamento dos subsistemas. Como resultado, esperam-se mais pontuações nos subsistemas do que no topo da organização. Todavia, nos níveis inferiores, dadas as resistências, elas serão mais facilmente acomodadas. Desse modo, se contrapõem a muitos modelos que preveem mudanças abruptas, mas geralmente causadas por fatores externos, em particular à opinião popular (também influenciando e sendo influenciado pela opinião popular). No entanto, na mesma linha do PET, destacam alguns trabalhos que consideram influência externa e interna como gatilhos para os choques de mudança em processos orçamentários. 
Embora estudos quantitativos tenham suscitado os principais contornos do PET, investigações mais qualitativas são exortadas por seus fundadores, para que se possam investigar melhor as relações aventadas pela teoria, como as fricções cognitivas e organizacionais, por exemplo.

Analisados os modelos de PET e MF, são dignas de nota suas similaridades e possibilidades de complementação. De fato, o modelo do PET dá mais ênfase aos aspectos institucionais, apresentando os subsistemas como locus mais estruturado para desenvolvimento das interações, em que poderiam atuar os múltiplos fluxos de Kingdon. São ainda os subsistemas o espaço onde a maior parte dos participantes visíveis e onde praticamente a totalidade dos invisíveis operam. A ação do empreendedor da política, em congregar os fluxos, está diretamente relacionada à formação da imagem da política capaz de acessar o nível da macropolítica (ou da agenda governamental).

Similaridades e diferenças entre os modelos dos MF e PET também são objeto da atenção de Capella (2006). Na avaliação da autora, ambos creditam à definição de uma questão ou situação o aspecto central na formação da agenda, quer por meio da imagem da política e contexto institucional, em seus constituintes empíricos e emocionais, quer por meio de eventos focalizadores. Os dois modelos também conferem grande papel ao presidente na definição da agenda. Além disso, rompem com uma visão de causa-efeito ao analisar a formação das agendas, oferecendo uma análise mais fluida e complexa, em que as ideias têm papel central. Por outro lado, diferem na ênfase ao papel das eleições, da mídia, de grupos de interesse na formação das agendas. Diante de tantos elementos comuns e complementares, uma proposta que proponha a integração dos modelos, recuperando a fluidez de Kingdon sem negligenciar os aspectos institucionais do PET, mostra-se alvissareira.

\section{Modelo conceitual e procedimentos metodológicos}

Para analisar a formação da agenda governamental no caso da desigualdade racial no ensino superior, propõe-se um modelo conceitual integrado (Figura 1). Inicialmente, considera o caráter multinível do fenômeno, observando não apenas a formação da agenda no nível dos subsistemas, mas também a mudança em processo de difusão. Nesse processo, pode-se verificar que os fluxos dos problemas, soluções e políticas convergem em janelas de oportunidades tanto no subsistema como no nível da macropolítica, considerando, todavia, elementos coincidentes ou não, em cada fluxo.

Por fim, além dos fluxos, verifica-se a influência do processo de mudança nos subsistemas, alterando a imagem da política, rompendo monopólios interpretativos e promovendo alteração nas agendas governamentais, que podem ou não resultar 
em mudanças também nesse patamar. Para compreender essa dinâmica, foi adotada uma estratégia de pesquisa qualitativa, com recurso da triangulação de dados.

Figura 1 - Modelo conceitual: Múltiplos Fluxos em análise multinível

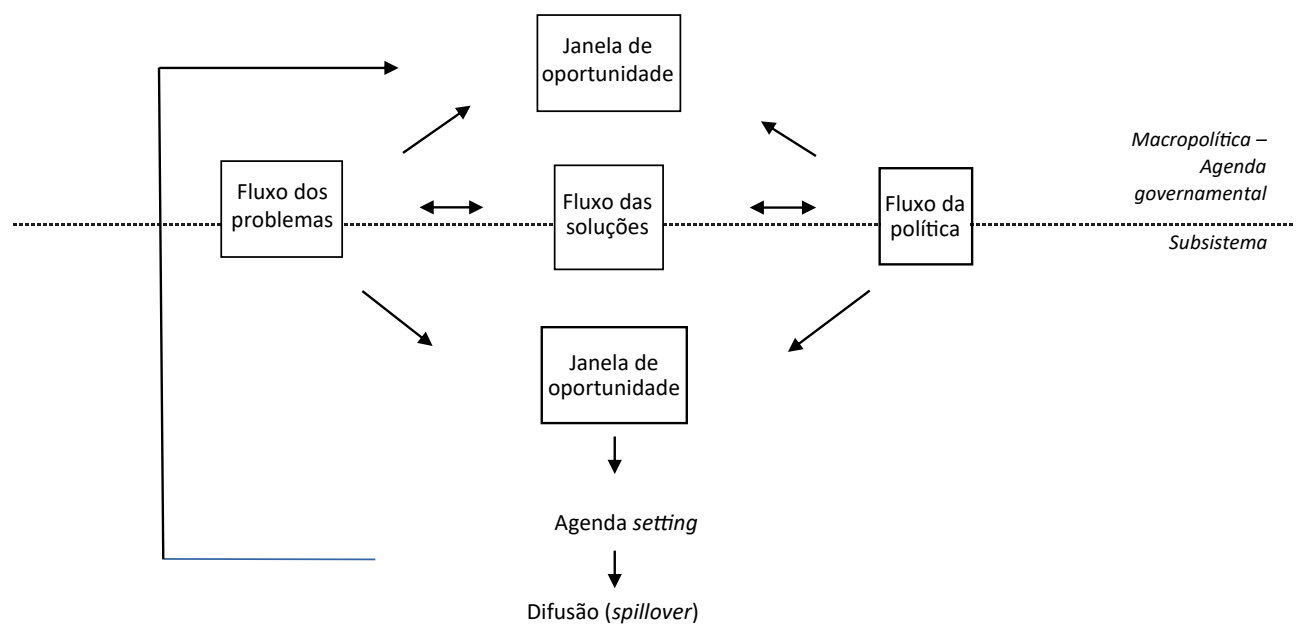

Fonte: Elaboração própria. Baseado em Kingdon (2007), Capella (2006), Jones e Baumgartner (2012).

Para alcançar o objetivo desta pesquisa - qual seja, analisar o processo de formação de agenda governamental em relação ao tema da desigualdade racial no acesso ao ensino superior -, foi delineada estratégia de pesquisa que recorreu à triangulação de fontes de dados (GUION, 2002). Inicialmente, foram apreciados documentos e estudos relativos à desigualdade racial no Brasil, em especial no ensino superior, e materiais sobre as ações afirmativas implementadas para enfrentamento desse problema (leis, estudos, pesquisas e relatos de experiências). Procurou-se identificar elementos que compuseram os múltiplos fluxos indicados no referencial teórico.

Para analisar o fenômeno também sob a perspectiva de participantes-chave, utilizaram-se notas taquigráficas da audiência pública (AP) convocada pelo Supremo Tribunal Federal (STF) para subsidiar o processo da Arguição de Descumprimento de Preceito Fundamental (ADPF) no $186^{4}$. Essa ação foi impetrada pelo partido atualmente conhecido como Democratas, contra o programa de cotas para negros desenvolvido pela UnB. A AP foi realizada entre 3 e 5 de março de 2010, com a participação de 44 oradores, entre representantes das partes, de movimentos sociais, de universidades, do governo, de associações de classe e especialistas. ${ }^{5}$ Essa audiência pública representou um marco no debate sobre cotas nas universidades,

\footnotetext{
${ }^{4}$ É o Recurso Extraordinário 597.285/RS contra o sistema de cotas na UFRGS.

${ }^{5}$ A relação completa dos habilitados para participar da audiência pública pode ser conferida no site do STF (http:// www.stf.jus.br/portal/cms/verNoticiaDetalhe.asp?idConteudo=118350\&caixaBusca=N).
} 
além de reunir um conjunto amplo e representativo de atores envolvidos diretamente na aplicação da política ou no debate público que a envolveu. Por essa razão, os discursos pronunciados nessa ocasião foram escolhidos para análise, pois se aproximam de uma síntese sobre o debate relativo à temática naquele momento.

\section{Resultados: a formação da agenda segundo atores-chave}

A análise empreendida possibilitou identificar elementos integrantes dos fluxos de problemas, política e soluções, conforme a abordagem teórica proposta por Kingdon (2011), a fim de recompor os processos que permitiram estabelecer a formação de agenda. A dinâmica desses fluxos procura explicar os meios pelos quais o tema da desigualdade racial no acesso ao ensino superior, persistente na história nacional, passou a ser visto como questão importante para o governo e alcançou as agendas governamental e de decisão, em uma conjunção dos fluxos de problemas, políticas e soluções em diferentes níveis. Para cada fluxo, são apresentadas a seguir as evidências captadas na pesquisa documental.

\section{Fluxo dos problemas}

Uma situação passa a ser conhecida ou ter sua magnitude considerada por meio de indicadores, eventos foco ou mesmo resultado de iniciativas governamentais (feedback). Ampla oferta de dados estatísticos mostravam a magnitude das desigualdades entre brancos e negros em vários campos sociais. De fato, número crescente de estudos procurava documentar fartamente os níveis diferenciados de acesso a bem-estar e ativos segundo a cor ou raça dos indivíduos. Essa geração de conhecimento sobre a situação social da população negra se consolidou tanto em bases nacionais fornecidas pelo IBGE ou registros administrativos (cadastros e registros utilizados em programas governamentais), como em avaliações específicas desenvolvidas por diversas organizações (ETHOS, 2010; Instituto de Pesquisa Econômica Aplicada, 2015; PAIXÃo et al., 2010). No entanto, como afirmam Paixão e Rosseto (2012), apesar da melhoria na visibilidade estatística da população negra, ainda restam níveis diferenciados de empenho das instituições para garantir coleta e tratamento adequados dos dados. Além disso, igualmente falta empenho no uso de informações com recorte transversal para retroalimentação das políticas públicas.

Alguns episódios, ocorridos em diferentes tempos e escala, foram considerados como "gatilhos" para o reconhecimento do problema ou de sua magnitude. Em um nível mais amplo, pode-se destacar a III Conferência Mundial Contra o Racismo, Discriminação Racial, Xenofobia e Intolerâncias Correlatas, realizada em 2001, em Durban, na África do Sul, com a participação de mais de 16 mil participantes de 
173 países. A conferência resultou em uma Declaração e Plano de Ação dos quais o Brasil é signatário (DECLARAÇÃo..., 2001) e promoveu grande mobilização nacional e internacional sobre o racismo e suas repercussões. Importa destacar o papel dos eventos nacionais preparatórios para conferência, que promoveu relevante atividade interna e repercussão sobre a questão racial, inclusive no âmbito da educação e das ações afirmativas (SANTOS, 2014).

No nível das IES, as oportunidades de debate interno desvelaram a situação em tela, em busca de reconhecimento do problema da desigualdade racial e de medidas para seu enfrentamento. No caso específico da UnB, foi relatado que um incidente racial promoveu debate sobre o tema, consolidando-se como um evento foco para a formação de agenda naquela instituição. Tal incidente refere-se a um episódio de reprovação, em uma disciplina, do único aluno negro a cursar o doutorado em Antropologia até então. Ao caso, foi atribuída conotação racial, que teve desdobramentos institucionais (FERRAZ, 2013).

Cabe ainda pontuar que os resultados insuficientes de programas governamentais universais também contribuíram para descortinar o problema da desigualdade racial, demandando ações diferenciadas. No entanto, como destacam Silva e outros (2011), o monitoramento e avaliação de programas transversais - que perpassam diferentes políticas setoriais -, como é o caso da política racial, carecem de maior visibilidade nos atuais mecanismos de orçamento e planejamento governamentais. Essa lacuna limita o monitoramento e avaliação dessas ações e, consequentemente, um feedback adequado.

Como pode ser observado, há diferentes níveis na identificação do problema (internacional, nacional, local), que serão tratados posteriormente.

Conforme a abordagem dos MF, além de ser revelado, um problema precisa ser percebido como tal, encetando mobilização para alterar o quadro. Nesse caso, a comparação internacional pode promover mudança de percepção e "desnaturalizar" as situações. Essa avaliação pode ser encontrada nas palavras do prof. Kabengele Munanga, sobre a desigualdade racial no Brasil (STF, 2010, p. 230):

Esse quadro é considerado como gritante quando comparado ao dos outros países que convivem ou conviveram com as práticas racistas como os Estados Unidos e a África do Sul. Os dados ao nosso conhecimento mostram que, na véspera do fim do regime do apartheid, a África do Sul tinha mais negros com diploma superior que o Brasil de hoje, incluindo o líder da luta antiapartheid, Nelson Mandela. Só este exemplo basta para mostrar que algo está errado no país da "democracia racial" que precisa ser corrigido. 
O confronto com valores sociais também é apontado como meio de mobilização para enfrentamento de um problema identificado. Nesse sentido, os valores trazidos pela Constituição Federal (CF) de 1988, além de evidenciar a responsabilidade do Estado na promoção da igualdade racial, ainda defendem o pluralismo, visto como constantemente afrontado pela exclusão de parcela da sociedade de diversos espaços. A afronta a esses valores foi constantemente mencionada na AP (STF, 2010, p. 14; 370):

O que acontece com a Constituição de 1988? Ela vem reconhecer exatamente o caráter plural da nossa sociedade nacional (Debora Duprat, PGR).

O espírito de reforma social, consagrado na nossa nova Constituição continua a inspirar a luta por direitos e pela realização do sonho democrático da igualdade (JOÃo FERES, UFRJ).

\section{Fluxo da política}

$\mathrm{Na}$ análise empreendida, foi possível identificar algumas categorias apresentadas pela abordagem dos MF como parte da dinâmica política que circunscreveu a formação da agenda. Como inicialmente exposto, o tema do racismo e das desigualdades raciais, por muito tempo, foi considerado tabu, apoiado no mito da democracia racial, que negava tanto as desigualdades como a discriminação tendo em vista o caráter miscigenado da população. Desvelar essa questão torna-se embate político importante na sociedade brasileira, o que justifica o tom acalorado dos debates em torno do tema. Por essa razão, são bem compreensíveis os achados que reforçam o contexto de opinião pública em que reina o silêncio sobre o tema ou ainda a persistência da visão de democracia racial. Por outro lado, à medida que as iniciativas foram sendo implementadas, importantes controvérsias contribuíram para expandir o alcance do debate.

Como ressalta Kingdon (2007b, 2011), as janelas de políticas públicas são abertas por eventos tanto na área dos problemas como da política (janelas de problemas e janelas de política). Nesse sentido, essa efervescência permitiu, aos poucos, que novas vozes se posicionassem sobre o tema e que as vozes de sempre fossem amplificadas. As propostas de enfrentamento do problema foram ganhando adeptos em diferentes setores, mesmo que as resistências ainda permaneçam expressivas. O monopólio da política foi, aos poucos, sendo minado.

Momentos de mudanças também são apontados na literatura como elementos que podem criar janelas de política. Nesse caso, mudanças em diferentes níveis parecem ter propiciado a assunção de novos temas às agendas das IES e dos governos (estaduais e federal e, em menor medida, municipais). No âmbito 
nacional, o advento do Programa de Apoio a Planos de Reestruturação e Expansão das Universidades Federais (Reuni), que tinha como objetivo ampliar o acesso e permanência na educação superior, abriu a possibilidade para debate e revisão de diretrizes de várias instituições, além de nortear a criação de outras à luz das propostas em debate. Cabe destacar que a "ampliação de políticas de inclusão e assistência estudantil" era uma das diretrizes do Reuni ${ }^{6}$.

A política educacional também passou a enfrentar mudanças conceituais em direção à adoção de ações afirmativas. Além do Prouni, anteriormente mencionado, com bolsas de estudo com critério social e racial, há que se mencionar a aprovação, em 2003, de legislação que alterou a Lei de Diretrizes e Bases da Educação (LDB, Lei no 9.394/96), no sentido de incorporar a história da África e do negro no país nos currículos escolares. Essa diretriz permeou diversos programas do Ministério da Educação (MEC) para garantir a implementação da alteração da LDB, inclusive encetando a criação da Secretaria de Educação Continuada, Alfabetização e Diversidade (Secad), em 20047. Essas mudanças na política nacional podem ter trazido repercussões no nível das IES, que, por sua vez, foram também internamente alimentadas pelos debates próprios desenvolvidos na comunidade acadêmica. Assim, notadamente, no fluxo da política, houve uma dinâmica multinível na formação das agendas.

Por fim, identificam-se diferentes grupos de interesse envolvidos no debate: governo, especialistas, estudantes secundaristas, estudantes universitários, docentes, IES (administradores e diversos grupos internos), mídia, Legislativo, Judiciário, parlamentares, movimentos sociais, partidos e sociedade civil organizada. Cabe destacar a atuação constante do movimento negro na busca por melhores oportunidades educacionais. Como ressalta Santos (2014), a partir da década de 1990, ao longo percurso de denúncia do racismo e da discriminação empreendido pelo movimento negro, soma-se uma inserção gradual de suas demandas na agenda governamental.

A multiplicidade de participantes, visíveis e invisíveis, na dinâmica dos fluxos desse tema requer uma análise mais aprofundada, que pode ser objeto de profícuos estudos sobre a formação de coalizações de defesa das diferentes propostas e crenças.

\footnotetext{
${ }^{6}$ Decreto no 6.096, de 24 de abril de 2007, art. 2, V.

${ }^{7} \mathrm{~A}$ implementação dessa alteração legal é desenvolvida por meio de estratégias consolidadas no "Plano nacional de implementação das diretrizes curriculares nacionais para educação das relações étnico-raciais e para o ensino de história e cultura brasileira e africana", que se baseia nos seguintes eixos fundamentais: "1) fortalecimento do marco legal; 2) política de formação para gestores e profissionais da educação; 3) política de material didático e paradidático; 4) gestão democrática e mecanismos de participação social; 5) avaliação e monitoramento; e 6) condições institucionais" (BRASIL, 2009, p. 25).
} 


\section{Fluxo das soluções}

Janelas de problemas e de políticas não formam janelas de oportunidades efetivas se não houver alternativas de políticas públicas para fazer face aos problemas da agenda governamental. As alternativas são formadas em um processo independente em que os especialistas disputam soluções de políticas, em uma "sopa" de métodos, valores e instrumentos de implementação. Essas alternativas não são necessariamente construídas para um determinado problema, mas emergem dos círculos especializados ao encontro de determinadas demandas de ação no âmbito dos governos (KINGDON, 2007b, 2011; ZAHARIADIS, 2007).

Nos discursos proferidos na AP, foi possível identificar duas grandes vias de propostas de políticas, sob as quais se delinearam diferentes justificativas e critérios de implementação: melhoria do ensino básico ou ações afirmativas; políticas universais ou políticas focalizadas, por assim dizer. Essas alternativas, por certo, não são excludentes.

Propostas de ações afirmativas já vinham se desenhando no país há décadas, especialmente inspiradas nas experiências internacionais, notadamente no caso dos EUA e da Índia. De fato, há tempo já foram inclusive incorporadas no ordenamento jurídico brasileiro, como no caso de cotas para pessoas com deficiência e mais recentemente de cotas para candidaturas de mulheres nas eleições.

A ação afirmativa pode ser considerada como toda iniciativa que vise à correção de desigualdades por meio de tratamento diferenciado dos grupos em desvantagem. O conceito pode ser extraído da Convenção Internacional sobre a Eliminação de todas as Formas de Discriminação Racial de 1966, internalizada no ordenamento jurídico brasileiro três anos depois:

Não serão consideradas discriminação racial as medidas especiais tomadas com o único objetivo de assegurar progresso adequado de certos grupos raciais ou étnicos ou de indivíduos que necessitem da proteção que possa ser necessária para proporcionar a tais grupos ou indivíduos igual gozo ou exercício de direitos humanos e liberdades fundamentais, contanto que tais medidas não conduzam, em conseqüência, à manutenção de direitos separados para diferentes grupos raciais e não prossigam após terem sidos alcançados os seus objetivos (ONU, 1966, artigo I, 4).

Em uma classificação direcionada para o contexto do mercado de trabalho, as ações afirmativas (AA) podem ser classificadas como iniciativas de justiça afirmativa ou de preferência afirmativa. As primeiras têm o fito de estimular a participação de indivíduos de determinados grupos em processos seletivos ou apoiá-los de modo a garantir sua inserção competitiva em igualdade de oportunidades. As medidas de 
preferência afirmativa referem-se a "iniciativas que oferecem ou recusam o acesso a certos bens ou serviços com base na raça, gênero ou deficiência" (TOMEI, 2005, p. 12). Além da melhoria da escola pública, propostas de justiça afirmativa e de preferência afirmativa, nos termos adotados por Tomei (2005), dividiram o debate não somente na AP, mas também de modo mais geral.

Todavia, é certo que a principal proposta em xeque era a da preferência afirmativa, tanto por ter sido a mais difundida ao longo da última década (INCTI, 2012), como por ser objeto direto de questionamento judicial. O que estava sub judice, de fato, era tanto a pertinência dessa modalidade de política como os critérios adotados para sua implementação. Embora o instituto da preferência afirmativa já fosse adotado no país, o critério racial, todavia, aparece como inovação no âmbito das políticas públicas. Com efeito, a primeira universidade que adotou critério racial exclusivo (sem critério social) - a UnB - encontrou questionamento quase que imediato na Suprema Corte.

Diferentes alternativas e critérios de políticas foram levantados como opções defensáveis face ao problema da ausência de negros no ensino superior. Como identificou Kingdon (2007b, 2011), é um momento em que diferentes valores estão em disputa e que as alternativas são verificadas quanto à sua viabilidade técnica, valores da comunidade de especialistas e antecipação a possíveis restrições. $\mathrm{Na}$ ocasião da AP, a viabilidade técnica era uma questão secundária, haja vista o fato de que as grandes propostas de ação afirmativa, nas diferentes acepções e com diferentes formatos, já se encontravam não apenas em funcionamento, mas em pleno processo de difusão. A própria existência de diferentes experiências de IES com programas de ação afirmativa, em diversos formatos, acabava por ilustrar o atendimento dessa primeira etapa. De fato, estavam em disputa, ao longo do processo, os valores que embasavam as alternativas. Entre os valores e critérios defendidos pelos atores para implementação de um sistema de ação afirmativa, o conflito central localiza-se no critério de seleção de beneficiários, ou seja, cotas com critério social ou racial.

Por fim, cabe pontuar algumas antecipações de problemas levantadas pelos atores. A possibilidade de futuros conflitos raciais em decorrência da opção por esse critério, as dificuldades advindas do processo de identificação racial ou mesmo o questionamento sobre a competência dos estudantes foram apresentados como limites à solução proposta pela UnB e retrucados em reiterados posicionamentos.

\section{Fluxos, subsistemas e macropolítica}

Nas seções anteriores, verificou-se como os fluxos de problemas, soluções e políticas marcaram a dinâmica da formação de agenda no caso da desigualdade racial 
no ensino superior. Os elementos dos referidos fluxos atuaram, de forma conjunta ou independente, tanto no nível da macropolítica como no nível dos subsistemas. Ademais, a dinâmica do subsistema não aconteceu de forma incremental, como presume o PET. No âmbito das IES, houve mudanças transformativas, radicais, na forma de ingresso dos estudantes, inclusive com adoção de critérios inéditos e controvertidos, como foi o caso da Unb. Por sua vez, foi possível identificar um processo de difusão entre as IES públicas. Com início do processo em 2001, uma década depois, 129 das 304 IES públicas já adotavam algum tipo de ação afirmativa (INSTITUTO DE INCLUSÃo NO ENSINO SUPERIOR E NA PESQUISA, 2012; INSTITUTO NACIONAL DE ESTUdOS E PESQUISAS EdUCACIONAIS, 2014b) ${ }^{8}$. Esse processo de difusão contribuiu para redução das resistências (fricções), possibilitando mudança na imagem da política e alteração do monopólio interpretativo que se concentrava nos discursos sobre democracia racial e meritocracia.

Cabe também comentar que o processo de formação de agenda se deu tanto no sentido top-down como bottom-up (TRUE et al., 2007). Por um lado, mudanças na política educacional, como o Reuni, Prouni e introdução das diretrizes curriculares da educação étnico-racial, promoveram, ao longo dos anos 2000, alteração na imagem da política, com influência na percepção e gestão das IES. Por outro lado, os processos autônomos das IES ${ }^{9}$ (ou, em alguns casos, por legislação estadual e municipal), conforme relatado, promoveram mudanças mais transformativas ainda, impelindo uma reestruturação na macropolítica. Assim, no âmbito da agenda federal, além da atuação dos múltiplos fluxos na formação da agenda, há que se considerar a consistência e importância da dinâmica dos subsistemas na conformação dos fluxos.

Outro ponto de destaque na análise é o papel dos atores. Como aponta Capella (2006),

Central ao modelo de Kingdon é a idéia de que alguns atores são influentes na definição da agenda governamental, ao passo que outros exercem maior influência na definição das alternativas (decision agenda). O primeiro grupo de participantes é composto por atores visíveis, que recebem considerável atenção da imprensa e do público; no segundo grupo estão os participantes invisíveis, que formam as comunidades nas quais as idéias são geradas e postas em circulação (policy communities) (CAPELLA, 2006, p. 32).

No entanto, no processo de ascensão do tema das cotas à agenda governamental, nos diversos níveis, os especialistas, associados à geração de alternativas como

\footnotetext{
${ }^{8}$ Em 2001, 70 das 96 universidades federais e estaduais já tinham alguma ação afirmativa (CAMPOS; FERES JÚNIOR, 2013; Instituto Nacional de Estudos e Pesquisas Educacionais, 2012).

${ }^{9}$ Autonomia conforme dispositivo constitucional (art. 207).
} 
participantes invisíveis, tiveram papel fundamental tanto na definição da agenda como na proposição de alternativas, chegando a assumir grande relevância no processo, como foi visto na citada audiência pública. Ademais, no âmbito das IES, eram especialistas alguns dos integrantes dos conselhos decisórios e, portanto, essa divisão não foi essencial na análise em questão.

Para o modelo dos MF, a mídia exerce mais influência depois que a questão entra na agenda (CAPELLA, 2006). No entanto, no caso aqui analisado, dada a extensão do processo de formação multinível da agenda governamental, por mais de 10 anos em debate e difusão em nível de subsistema, houve grande repercussão da mídia, impelindo a formação da agenda em nível macropolítico.

Estudo de Campos e Feres Júnior (2013) sobre a repercussão midiática da política de ação afirmativa em universidades analisou 1054 textos publicados, em 2001 e 2011, no jornal O Globo. Segundo os autores, esse veículo foi pioneiro no tratamento do tema, tendo em vista que se situava no Rio de Janeiro, estado onde as ações afirmativas para ingresso em IES foram iniciadas. Os autores identificam que, apesar de o recorte socioeconômico ser majoritário nas iniciativas de AA, 87,7\% dos textos do jornal concentravam-se no critério racial. Considerando as categorias contrário, favorável, neutro, ambivalente e ausente, o estudo identificou que apenas $26 \%$ foram favoráveis às cotas enquanto $42 \%$ dos textos eram contrários (nesse caso, mais prevalecentes nas seções de carta aos leitores, editorais e nas notas). Essa tendência de tratamento do tema com uma prevalência negativa, embora em análise restrita a um jornal, demonstra como a mídia pode contribuir não apenas para reverberar a agenda governamental, mas também para pautá-la e construir uma imagem da política.

\section{Considerações finais}

O presente estudo teve como objetivo analisar o processo de formação de agenda governamental que culminou com a inclusão do tema da desigualdade racial no acesso ao ensino superior. Para tanto, recorreu-se ao referencial teórico dos múltiplos fluxos formulado por Kingdon e aprimorado por seguidores. A esse modelo, acresceram-se elementos do modelo do equilíbrio pontuado, a fim de abarcar a dinâmica multinível identificada no caso analisado.

No âmbito do fluxo dos problemas, verificou-se que a questão passou de uma mera situação a um problema importante na agenda governamental por meio de indicadores, eventos críticos e avaliação de outras iniciativas governamentais. No entanto, além desses elementos, o confronto com valores nacionais em desenvolvimento e comparações internacionais permitiu mobilização para seu enfrentamento. 
No fluxo da política, foi identificado relevante e diverso repertório de partes interessadas no problema, o que confluiu em um intenso debate público a ocupar espaços de ampla repercussão nacional. Nesse contexto, a opinião pública oscilava desde a negação e invisibilidade do tema, até uma visão mais plural e engajada para seu enfrentamento. Além desses elementos, processos de mudança multinível se mostraram cruciais para abrir espaço na agenda governamental para essa "nova" temática.

Por fim, a existência de ampla discussão sobre as alternativas para fazer face ao problema da desigualdade racial no ensino superior vinha se consolidando em uma década de experiências de ação afirmativa em dezenas de IES pelo país.

Assim, uma janela de oportunidade importante foi aberta, motivada, por um lado, por um processo de difusão de experiências de ação afirmativa e um conjunto maior de dados disponíveis sobre a situação, desvelando o problema; e, por outro lado, uma efervescência de debates e grupos de interesses disputando a interpretação das normas e das instituições em ambientes de mudança (STREECK; THELEN, 2005).

No entanto, como indicado anteriormente, essa dinâmica ocorreu de forma multinível. O processo de formação de agenda em nível federal se deu em meio a um processo de difusão ao nível das IES. Logo, a formação da agenda tanto ao nível das IES como ao nível federal passou por um efeito de spillover (KINGDON, 2007b, 2011), no qual a decisão em um nível favoreceu o debate e a formação de coalizões em outro patamar. O referencial dos MF, em que pese sua contribuição para análise dos elementos pré-decisórios, parece insuficiente para tratar de dinâmicas multinível.

Por sua vez, a abordagem do equilíbrio interrompido discute a formação de processos de mudança radical no sistema macropolítico como resultados de mudanças incrementais nos subsistemas a este vinculados. A dinâmica promovida pelos subsistemas provocaria alterações na imagem do problema e impulsionaria mudanças de maior envergadura (JONES; BAUMGARTNER, 2012). Logo, mostrouse uma fértil possibilidade aliar a abordagem dos múltiplos fluxos à reflexão sobre como os subsistemas caracterizados pelas IES se alteraram internamente e reconfiguraram a imagem do problema a ponto de pressionar a macropolítica.

Por fim, pode-se concluir que a janela de oportunidades reconstituída na análise, bem como a dinâmica de difusão nos subsistemas, ensejou a mudança no nível macropolítico evidenciada tanto pela decisão unânime do STF a favor das cotas com critério racial na UnB em 2012, como pela promulgação da Lei no 12.711/2012 (lei de cotas no ensino superior federal), apenas meses após o parecer do STF. A referida lei, no entanto, subordinou o critério racial ao social, além de tomar o segundo também de forma independente do primeiro. Na norma, o critério principal é a 
vinculação à escola pública; desse contingente, retiram-se subcotas por condição racial e de renda. Apesar da constitucionalidade do critério racial, o embate enunciado no fluxo das soluções permaneceu ao longo do processo de formulação, estabelecendo um critério intermediário na configuração final.

O desenvolvimento deste trabalho procurou trazer algumas contribuições ao debate do tema e das abordagens teóricas apreciadas. Investigar a trajetória dessa política afirmativa pode contribuir para a análise de sua implementação e resultados, além de identificar fatores críticos que mereçam ser monitorados para promover sua eficácia. A dinâmica de formação dessa agenda traz elementos significativos não apenas para compreender seus atuais embates, como para identificar questões fundamentais para seus processos de implementação e avaliação. Nessa direção, pode contribuir para análise de políticas implementadas por legislações, como a lei de cotas no ensino superior, reserva de vagas em concursos públicos (Lei $\mathrm{n}$ ㅇ 12.990/2014), ou ainda outras normativas, estaduais e municipais, que disciplinam igual objeto desde o início dos anos 2000 (SILVA; SILVA, 2014).

O estudo procura contribuir para o campo teórico ao propor uma análise multinível dos múltiplos fluxos de Kingdon, uma vez que a complexidade da dinâmica em tela mostra insuficiência do referencial isolado para análise da formação de agenda em contextos de diferentes subsistemas com dinâmicas e tempos independentes, alterando as agendas governamentais em diversos níveis. Há muita literatura sobre a adoção e implementação de ações afirmativas em IES, no entanto, este estudo focaliza a limitada produção sobre a formação dessa agenda governamental.

Diante de tanta informação disponível, esta análise limita-se a algumas referências, podendo aprofundar seus achados ao incorporar não só mais materiais sobre a formação da agenda nas IES, a partir de seus relatos internamente produzidos, como por meio de entrevistas com atores-chave, direcionadas especificamente para esse objetivo.

Novas oportunidades de estudos apontam para o caminho proposto do Zahariadis (2007), com vistas à utilização dos MF para analisar os processos de implementação dessas iniciativas. Outros estudos poderiam também ser encetados diante da multiplicidade de atores-chave, valores e interesses envolvidos. Análises dedicadas à formação de coalizações de defesa das diferentes propostas e crenças mostram-se igualmente promissoras nesse cenário.

\section{Referências bibliográficas}

BRASIL. Ministério da Educação. Secretaria Especial de Políticas de Promoção da Igualdade Racial. Plano Nacional de implementação das Diretrizes Curriculares Nacionais para educação das relações etnicorraciais e para o ensino de história e cultura afro-brasileira e africana. Brasília: MEC, 2009. 
CAIRNEY, Paul; JONES, Michael. Kingdon's multiple streams approach: what is the empirical impact of this Universal Theory? The Policy Studies Journal, v. 44, Issue 1, p. 37-58, 2016.

CAMPOS, Luiz Augusto; FERES JúNIOR, João. O Globo e as ações afirmativas: dez anos de cobertura (2001-2011). Textos para discussão GEMAA (IESP-UERJ), n. 2, p. 1-18, 2013.

CAPella, Ana Cláudia N.; BrasIL, Felipe G. Subsistemas, comunidades e redes: articulando ideias e interesses na formulação de políticas públicas. Revista do Serviço Público, Brasília, v. 66, n. 3, p. 449-474, 2015.

CAPella, Ana Cláudia N. Perspectivas teóricas sobre o processo de formulação de políticas públicas. BIB: Revista Brasileira de Informação Bibliográfica em Ciências Sociais. São Paulo: Anpocs, 2006. (p. 25 -52).

Declaração e programa de ação - IIl Conferência Mundial Contra o Racismo, Discriminação Racial, Xenofobia e Intolerâncias Correlatas (2001) [online]. Programa de ação adotado em 8 de setembro de 2001 em Durban, África do Sul. Brasília: FCP Palmares, 2001. http://www.unfpa.org.br/Arquivos/declaracao_durban.pdf. Acesso em: 21/11/2015.

INSTITUto ETHOS DE EMPRESAS E RESPONSABILIDADE Social (ETHOS). Perfil social, racial e de gênero das 500 maiores empresas do Brasil e suas ações afirmativas - Pesquisa 2010. São Paulo, 2010.

FerRAz, Beatriz et al. Sistema de cotas da Universidade de Brasília completa dez anos. Campus on line - Jornal-laboratório, Faculdade de Comunicação Universidade de Brasília, 2013. http://campus.fac.unb.br/arquivo/campus12014/ universidade/item/2757-uma-década-de-inclusão. Acesso em: 20/11/2015.

GotTEMS, L. et al. O modelo dos múltiplos fluxos de Kingdon na análise de políticas de saúde: aplicabilidades, contribuições e limites. Saúde Soc. São Paulo, v. 22, n. 2, p. 511-520, 2013.

GUION, L. A. Triangulation: establishing the validity of qualitative studies. University of Florida, FCS, 6014, 2002.

INSTITUTO DE INCLUSÃo NO ENSINO SUPERIOR E NA PESQUISA (INCTI). Universidade de Brasília (UnB). Mapa de Ações Afirmativas [online]. Brasília: INCTI, junho de 2012. http://www.inctinclusao.com.br/acoes-afirmativas/mapa. Acesso em: 21/11/2015. Instituto Nacional de Estudos e Pesquisas Educacionais (Inep). Sinopse estatística da educação superior - 2000 [online]. Brasília: Inep, 2001.

2012.

. Sinopse estatística da educação superior - 2011 [online]. Brasília: Inep,

. Sinopse estatística da educação superior - 2013 [online]. Brasília: Inep, 2014a.

Censo da educação superior 2012: resumo técnico. - Brasília: Inep, 2014b.

INSTITUTO de Pesquisa EConômica Aplicada (IPEA). Anexo estatístico, Ipea. Políticas Sociais - acompanhamento e análise, n. 23. Brasília: Ipea, 2015. 
JONES, Bryan D.; BAUMGARTNER, Frank R. From there to here: punctuated equilibrium to the General Punctuation Thesis to a Theory of Government Information Processing. The Policy Studies Journal, p. 1-19, 2012.

Kingdon, John W. Como chega a hora de uma ideia. In: SARAVIA, E.; Ferrarezi, E. Políticas Públicas - Coletânea. v. 1, Brasília, Enap, 2007a.

. Juntando as coisas. In: Saravia, E.; Ferrarezi, E. Políticas Públicas Coletânea. v. 1. Brasília: Enap, 2007b.

. Agendas, alternatives and public policies. 2. ed. Boston: Longman, 2011.

ORGANIZAÇÃO DAS NAÇÕES UNIDAS (ONU). Convenção Internacional sobre a Eliminação de todas as Formas de Discriminação Racial, 1966.

OsóRıO, R. G. Desigualdade racial e mobilidade social no Brasil: um balanço das teorias. In: THEODORO, M. (Org.). As políticas públicas e a desigualdade racial no Brasil: 120 anos após a abolição. Brasília: Ipea, 2008.

PAIXÃo, Marcelo; RossetTo, Irene. Levantamento das fontes de dados estatísticos sobre a variável cor ou raça no Brasil contemporâneo: terminologias classificatórias, qualidade das bases de dados e implicações para as políticas públicas [online]. In: Encontro AnUAL dA ANPocs, 36., 2012, Águas de Lindoia. Anais... Águas de Lindóia (SP): Anpocs, 2012.

PAIXÃo, Marcelo et al. (Orgs.). Relatório Anual das Desigualdades Raciais no Brasil; 2009-2010. Rio de Janeiro: Editora Garamond, 2010.

Rıos, Flavia. O protesto negro no Brasil contemporâneo (1978-2010). Lua Nova, São Paulo, n. 85, p. 41-79, 2012.

SANTOS, Sales Augusto. Educação: um pensamento negro contemporâneo. Jundiaí: Paco Editorial, 2014.

Silva, Silvio José Albuquerque. Combate ao racismo. Brasília: Funag, 2008.

SILVA, Tatiana D. Panorama social da população negra. In: SILVA, T. D.; GoES, F. L. Igualdade racial no Brasil: reflexões no Ano Internacional dos Afrodescendentes. Brasília: Ipea, 2013. SILVA, T. et al. Planejamento e financiamento das políticas de igualdade racial: possibilidades para o Plano Plurianual 2012-2015. Nota técnica Disoc n. 7. Brasília: Ipea, 2011.

SILVA, Tatiana D.; SILVA, Josenilton M. Reserva de vagas para negros em concursos públicos: uma análise a partir do Projeto de Lei 6.738/2013 [online]. Nota técnica Disoc n. 17. Brasília: Ipea, 2014.

SUPREMo TRIBUnAl FEDERAL (STF). Notas Taquigráfica: Arguição de Descumprimento de Preceito Fundamental 186/Recurso Extradordinário 597.285 [online]. Brasília: STF, 2010. http://www.stf.jus.br/arquivo/cms/processoaudienciapublicaacaoafirmativa/ anexo/notas_taquigraficas_audiencia_publica.pdf. Acessado em 18 nov. 2015.

STREECK, Wolfgang; THELEN, Kathleen. Introduction: institutional change in advanced political economies. In: STREECK, W.; THELEN, K. (Eds). Beyond continuity: institutional change and advanced political economies. New York: Oxford University Press, 2005. 
THEODORO, M. A formação do mercado de trabalho e a questão racial no Brasil. In: THEODORO, M. (Org.). As políticas públicas e a desigualdade racial no Brasil: 120 anos após a abolição. Brasília: Ipea, 2008.

TOMEI, M. Ação afirmativa para a igualdade racial: características, impactos e desafios. Brasília: OIT, 2005.

TRUE, James et al. Punctuated-Equilibrium Theory; explaining stability and change in public policy making. In: SABATIER, Paul (Ed.). Theories of the policy process. Boulder: Westview Press, 2007.

WeIBLE, Christopher M.; SCHLAGER, Edella. The Multiple Streams Approach at the theoretical and empirical crossroads: an introduction to a special issue. The Policy Studies Journal, v. 44, n. 1, 2016, p. 5-12.

ZAHARIADIS, Nikolao. Multiple Streams Framework: structure, limitations and prospects. In: SABATIER, Paul. (Ed.). Theories of the policy process. Boulder: Westview Press, 2007.

Tatiana Dias Silva

Possui mestrado em Administração pela Universidade Federal da Bahia (UFBA). Atualmente é Técnica de Planejamento e Pesquisa do Instituto de Pesquisa Econômica Aplicada (Ipea). Contato: tatiana.silva@ig.com.br. 